\title{
POR QUEM NOS COMOVEMOS? REFLEXÕES SOBRE NOSSOS ENQUADRAMENTOS BÉLICOS
} ¿POR QUIÉN NOS CONMOVEMOS? REFLEXIONES SOBRE NUESTROS
MARCOS BELICOS
WHO DO WE CRY FOR? REFLECTIONS ON OUR WAR FRAMEWORKS

Resenha de:

Butler, J. (2015). Quadros de guerra: quando a vida é passivel de luto? (S. T. M. Lamarão \& A. M. Cunha, Trads.) Rio de Janeiro: Civilização Brasileira.

Pela tela, pela janela Quem é ela, quem é ela $\mathrm{Eu}$ vejo tudo enquadrado Remoto controle. (Calcanhotto, 1992)

Diante das imagens contemporâneas de violência e guerra, tão explícitas e acessíveis, porque nos comovemos com algumas mortes e com outras não? Publicada no Brasil em 2015 a tradução do livro "Quadros de Guerra: quando a vida é passível de luto?", de Judith Butler, aponta intensamente essa provocação. Trata-se de um esforço teórico que reúne cinco ensaios para compreender as guerras contemporâneas. A autora, reconhecida por suas discussões a respeito de gênero e sexualidade (Butler, 2003), busca colocar em análise certas formas de ver que se constituem em enquadramentos a partir dos quais algumas vidas são concebidas como vidas humanas e por isso desencadeiam processos de luto. Em contrapartida, algumas outras vidas não são apreendidas como tal e portanto não geram comoção quando lidas dentro desses quadros de guerra.

O desafio de compreender quais vidas poderão ser enquadradas como vidas busca "ampliar as reivindicações sociais e políticas sobre os direitos à proteção" (p. 15) e, para tanto, coloca em questão certa ontologia corporal. Butler instiga a pensar em ontologia não como estruturas fundamentais, mas como questionamentos sobre precariedade, vulnerabilidade, dor, interdependência, trabalho, reivindicações sobre linguagem e pertencimento social.
O 'ser' do corpo ao qual essa ontologia se refere é um ser que está sempre entregue a outros, a normas, a organizações sociais e políticas que se desenvolveram historicamente a fim de maximizar a precariedade para alguns e minimizar a precariedade para outros. (p. 15)

Ao longo da introdução, a autora busca costurar os cinco ensaios do livro, articulando principalmente a questão do enquadramento e do luto como estratégia de questionamento ontológico. Além disso, a palavra "enquadre", ou o ato de "enquadrar" carrega uma abertura de significados. Pode ser entendida como certa possibilidade de emoldurar e tornar inteligível. Ou ainda, enquadrar poderia ser compreendido como o ato de incriminar, atribuir certo estatuto de culpa a alguém. Quando o enquadre toma esse segundo contorno, as possibilidades de luto e comoção vão se tornando mais restritas.

Para compreender essas operações, é imprescindível analisar a característica mutante do próprio enquadramento. Para manter-se em operação o enquadre produz rompimentos. $\mathrm{Na}$ necessidade de trânsito dos seus limites, o enquadramento sugere certo afrouxamento, potência de novas trajetórias de comoção. Produzir novos enquadramentos não significa apenas encontrar novos conteúdos, como propõe a mídia alternativa, mas colocar em xeque a realidade, até então, aceita sem discussão.

Aprofundando essas questões, Butler expõe a noção de precariedade. Na introdução, esse conceito aparece a partir da discussão sobre aborto, quando os argumentos giram entre o direito à liberdade de escolha ou o direito à vida. Essa contraposição será contestada, porque nos levaria a uma infértil discussão sobre o que é a vida e o que é a pessoa. Não se dá no nível do que “está vivo ou não, nem se tem o estatuto de 'pessoa'; trata-se de saber, na verdade, se as condições sociais de sobrevivência e prosperidade são ou não possíveis" (p. 38). 
Interessante pensar no paradoxo da precariedade como algo que marca a todos ao mesmo tempo em que se faz necessário reconhecer que existem processos arbitrários que potencializam a precariedade para alguns. Esse paradoxo possibilitaria assumir compromissos políticos e sociais de oferta de suportes para minimizar a condição precária da vida e tornála vivível. Se, "a decisão de abortar um feto pode perfeitamente estar embasada na suposição de que as formas de suporte social e econômico necessários para tornar aquela vida vivível estão ausentes" (p. 41), essa não seria uma decisão contrária ao direito à vida.

Nesse sentido, os enquadramentos de guerra gerenciam a precariedade, controlam e potencializam a comoção, possibilitando que algumas vidas tenham sua condição precária maximizada e outras a tenham minimizadas. Esse gerenciamento produz relações ambíguas de algumas populações com o Estado, como instaurador de violência, mas também como instância de proteção e garantia de direitos.

Em cada um dos ensaios, Butler empreende a análise de diferentes enquadramentos de guerra, como "maneiras de esculpir seletivamente a experiência, como algo essencial à condução da guerra" (p. 47). No primeiro capítulo, a noção de responsabilidade é colocada em questão através das situações onde, em nome da responsabilidade global, alguns países justificam guerras para "levar a democracia" a outros países. Essas justificativas constroem os enquadramentos da guerra que acarretam distribuições desiguais do luto público. Para além das fronteiras geográficas e políticas, os quadros de guerra produzem fronteiras para respostas afetivas a perdas humanas, estabelecendo limites para a comoção e para vidas que serão, ou não, consideradas efetivamente vidas.

Se a guerra se sustenta por um enquadramento que nos faz apreender a vida de maneira seletiva, poderíamos questionar quais as possibilidades de ruptura desses enquadramentos. Para tanto, Butler recorre a poesias escritas por prisioneiros de Guantánamo, identificadas pelo Pentágono como risco para a segurança nacional. Shaker Abdurraheem Aamer questiona a guerra em nome da paz em seu poema: "Paz, eles dizem. Paz de espírito? Paz na Terra? Paz de que tipo? ... Matar é tão simples assim? É esse o plano deles? Claro que sim! Eles conversam, eles discutem, eles matam - Eles lutam pela paz" (p. 90). A poesia aqui explicita a tirania das justificativas da guerra na seletividade de vidas a serem protegidas e na descartabilidade de vidas a serem torturadas e mortas em nome da liberdade e da paz. Mesmo que não interrompam a guerra, os poemas produzem efeitos políticos.
No ensaio 2 a fotografia é colocada em análise, a partir de Sontag, para compreender se ainda carregaria a potência de instigar reações políticas diante da exposição da dor dos outros. Butler chama atenção para as transformações históricas nas fotografias de guerra e as formas atuais de regulação do Estado sobre as imagens e as coberturas comprometidas. Simulando apenas "revelar" a realidade, as imagens podem fabricar o que será perceptível, através do que mostram, como mostram e como nomeiam. Nesse sentido, a fotografia não seria em si torturante ou libertadora, mas um dispositivo que pode ser instrumentalizado para nos perseguir, nos paralisar ou nos impor ações políticas. Se há uma função crítica para as imagens de guerra, seria a alternativa de enxergar os enquadramentos que nos cegam.

O terceiro ensaio coloca em questão a articulação discursiva entre políticas sexuais e modernidade analisando a forma como posturas "progressistas" e seculares em relação à sexualidade se transformam em instrumentos de demarcação entre culturas "avançadas" e culturas "atrasadas". Configura-se um triste encaminhamento das lutas por liberdades sexuais usadas como mecanismos de intolerância e coerção, especialmente contra imigrantes islâmicos. Instaurase uma dissociação entre lutas pela liberdade sexual, lutas por liberdade religiosa e lutas antirracistas, disfarçando os mecanismos estatais coercitivos que violam essas esferas. Para tanto, Butler coloca em questão as práticas homofóbicas e misóginas presentes na própria missão civilizatória, utilizando tortura como técnica de "modernização".

Sexualidade e religião continuam no ensaio seguinte, quando se enfrentará o debate sobre identidade e norma, colocando em questão o "fundamento" do sujeito. Esse debate será criticado através da forçosa oposição entre gay e muçulmano, que em termos de identidade enclausura muçulmanos como essencialmente homofóbicos e gays como antiislâmicos. Tais enquadramentos normativos e binários instauram cristalizações e ignorâncias culturais, ou o não pensamento. A alternativa elencada por Butler seria atentar para os poderes estatais regulatórios que "orquestram o debate e manipulam os termos para criar um impasse político" (p. 211). Essa alternativa permitiria inclusive analisar situações de violência para além da dicotomia entre terrorismo e guerras justificadas, além de problematizar versões de multiculturalismo que se equivocam ao presumir antecipadamente formas de sujeito.

No último ensaio, o livro problematiza o apelo à não violência, instigando a pensar a quem se dirige o discurso da não violência. A análise retoma a tese 
da violência como formadora do sujeito, chamando atenção para o processo de iterabilidade, onde a norma permanece por movimentos de repetição e ruptura. A não violência não é um princípio, uma virtude ou uma posição passiva, mas uma prática. Pode ser uma prática falível, mas não revidar um ato de violência possibilitaria expor a "brutalidade unilateral" (p. 249), expõe a relação com o outro. Poderia então a não violência ser compreendida como resistência se de certa maneira romper "os enquadramentos por meio dos quais a guerra é forjada" (p. 259).

\section{Das guerras brasileiras}

Cabe então pensar de que maneira a análise dos enquadramentos bélicos tem utilidade no Brasil, contexto em que não há declaração explícita de guerra. A potência dessa análise se consolida quando evidenciamos a maximização da condição precária de alguns contextos e sujeitos no Brasil, ou seja, a "condição politicamente induzida na qual certas populações sofrem com redes sociais e econômicas de apoio deficientes e ficam expostas de forma diferenciada às violações, à violência e à morte" ( $p$. 46).

Nesse sentido, as guerras brasileiras são travadas internamente, disputando e construindo noções de sujeitos e vidas que são passíveis de luto. Proponho colocar em questão dois cenários que evidenciam enquadramentos bélicos, tanto na linguagem quanto nos efeitos de perdas humanas e gerenciamento da comoção no Brasil: enquadramentos relacionados a gênero/sexualidade e enquadramentos relacionados a classe/raça.

Problematizar gênero e sexualidade como enquadramentos a partir dos quais algumas vidas serão alvo de violação possibilita compreender a fabricação de vulnerabilidades. Dois vídeos circularam no Brasil entre 2016 e 2017 e expõem a tortura e desumanização das marcas de gênero e sexualidade. Em 25 de maio de 2016, espalha-se na internet o vídeo de um estupro coletivo cometido quatro dias antes contra uma jovem de 16 anos no Rio de Janeiro (Rossi, 2016). Em março de 2017, circula na internet a filmagem do espancamento de uma travesti de 42 anos que na sequência foi assassinada. $\mathrm{O}$ crime aconteceu no dia 15 de fevereiro no Ceará (Dimitri, 2017).

As duas cenas colocam em questão um certo enquadramento que torna possível, mesmo representando a captura de crimes (estupro e homicídio), as imagens serem produzidas sem constrangimento. Pelo contrário, a interação entre quem filma e quem está sendo filmado demonstra participação ativa ou, pelo menos, cumplicidade, beirando exibicionismo e orgulho pela violência perpetrada. Assim como nas imagens de guerra, a tortura aparece "em plano aberto, diante da câmera, até mesmo para a câmera" (p. 128).

Entretanto, a circulação da imagem produz deslocamentos e, de certa maneira, permite analisar o modo como agem esses enquadramentos que modificam a intensidade da comoção. Entram em cena julgamentos sobre a conduta das vítimas como condição para reconhecer a violência e gerar indignação - o fato de ser travesti ou o fato de ser mãe aos 16 anos e estar numa festa, por exemplo.

Já em relação a raça/classe, a qualificação de vidas que não são dignas de proteção aparece articulada à questão do uso de drogas, produzindo um enquadramento de guerra. Em São Paulo, dia 26 de fevereiro de 2017 um menino de 13 anos morreu em frente a uma lanchonete após a abordagem de funcionários do local (Cruz, 2017). A questão que rondou o caso dizia respeito ao uso ou não de drogas. Essa característica possibilita o deslizamento do enquadre sobre esse adolescente ou como alguém pedindo comida e, portanto, capaz de produzir comoção ou como um jovem usuário, entendendo a morte como uma consequência de seus atos.

Outra cena para compreender o funcionamento desses enquadramentos que definem possibilidades de comoção aconteceu em ações urbanas de intervenção com usuários de crack em São Paulo. Um cenário bastante desumanizado, acostumado com a colagem de características de raça e classe, produz espanto quando evidencia nesse território um jovem loiro de classe média-alta, que ficou conhecido nacionalmente após o assassinato dos pais (Brandalise \& Perez, 2017). O que está em questão nessa cena como deslizamento do enquadre não é a utilização da droga, mas o histórico do jovem, possibilitando o reconhecimento de humanidade negado a quem por lá se encontra. É claro que esse não é qualquer sujeito, estamos aqui vendo funcionar um quadro de classe e raça/etnia.

Nesse sentido, mesmo sem declaração formal de guerra, vemos enquadramentos funcionando cotidianamente na realidade brasileira. Em algumas situações, é possível enquadrar o enquadramento, ou seja, colocar em questão: quais contornos tornam algumas vidas humanas menos valiosas que outras? Quais são as figuras vivas hoje que não alcançam o estatuto de vida humana?

Diante das cenas relatadas podemos pensar em vidas que possuem contornos específicos: travestis, transexuais, mulheres, usuários de drogas 
ilícitas, negros, pobres, autores de delitos. Há um jogo articulado e móvel entre essas formas de enquadramento que circunscreve e incrimina sujeitos. Enquadrar o enquadramento seria não uma análise dispersa centrada na reflexividade, mas colocar em questão a própria moldura, que "nunca conteve de fato a cena a que se propunha ilustrar, que já havia algo de fora, que tornava o próprio sentido de dentro possível, reconhecível” (p. 24).

Os quadros de guerra no Brasil aparecem também no uso da linguagem bélica: guerra às drogas, guerra contra a criminalidade, pacificação, etc; produzindo alguns inimigos a serem abatidos. Entretanto, o uso desse vocabulário de guerra constrói também estratégia para fazer ver a abrangência desses enquadramentos e a maximização de precariedade para algumas vidas: genocídio da juventude negra, femininício, genocídio da população trans. Esse vocabulário aparece em debates que pautam a construção de políticas específicas para resistir aos efeitos cruéis desses enquadramentos.

Provocar rupturas nesses enquadramentos seria colocar em xeque uma realidade aceita sem discussão. A disputa de sentidos ganha, através da arte, uma alternativa para questionar a aceitação cotidiana da guerra.

Eu não sou da paz. Não sou mesmo não. Não sou. Paz é coisa de rico. Não visto camiseta nenhuma, não, senhor. Não solto pomba nenhuma, não, senhor. Não venha me pedir para eu chorar mais. Secou. A paz é uma desgraça... Quem vai ressuscitar meu filho, o Joaquim? Eu é que não vou levar a foto do menino para ficar exibindo lá embaixo. Carregando na avenida a minha ferida. Marchar não vou, muito menos ao lado de polícia. Toda vez que vejo a foto do Joaquim, dá um nó. Uma saudade. Sabe? Uma dor na vista. Um cisco no peito. Sem fim. Uma dor. Dor. Dor. Dor. A minha vontade é sair gritando. Urrando. Soltando tiro. Juro. Meu Jesus! Matando todo mundo. É. Todo mundo. Eu matava, pode ter certeza. A paz é que é culpada. Sabe? A paz é que não deixa. (Freire, 2008, pp. 25-28).

Nesse sentido, "a não violência não é um estado pacífico, mas uma luta social e política para tornar a raiva articulada e efetiva" (p. 256), reconfigurando os sentidos de guerra e paz e evidenciando os efeitos que esses discursos produzem. Se, nossos enquadramentos bélicos brasileiros definem cotidianamente quem são os alvos da guerra e quem têm direito à paz e à proteção do Estado, é necessário enquadrar os enquadramentos.

\section{Referências}

Brandalise, C. \& Perez, F. (2017, 2 de junho) O drama de Andreas Von Hichthofen. Istoé. Recuperado de http://istoe. com.br/o-drama-de-andreas-von-richthofen/

Butler, J. (2003). Problemas de gênero: feminismo e subversão da identidade. Rio de Janeiro: Civilização Brasileira.

Butler, J. (2015). Quadros de guerra: quando a vida é passivel de luto? (S. T. M. Lamarão \& A. M. Cunha, Trads.) Rio de Janeiro: Civilização Brasileira.

Calcanhotto, A. (1992) Esquadros [Recorded by A. Calcanhotto]. In Senhas [LP]. Brasil: Columbia.

Cruz, B. S. (2017, 10 de março) Perito questiona laudo sobre morte de João Victor; defesa quer reconstituição do crime. Uol Notícias. Recuperado de https://noticias. uol.com.br/cotidiano/ultimas-noticias/2017/03/10/peritoquestiona-laudo-sobre-morte-de-joao-victor-defesa-querreconstituicao-do-crime.htm

Dimitri, T. (2017, 19 de março) Morte de Dandara: foram pelo menos três sessões de tortura. O Povo. Recuperado de http:// www.opovo.com.br/noticias/fortaleza/2017/03/morte-dedandara-foram-pelo-menos-tres-sessoes-de-tortura.html

Freire, M. (2008) Rasif - mar que arrebenta. Rio de Janeiro: Record, 2008.

Rossi, M. (2016, 31 de maio) Nova delegada do Rio garante: está provado o estupro coletivo da jovem de 16 anos. El País, Brasil. Recuperado de http://brasil.elpais.com/ brasil/2016/05/30/politica/1464631347 909205.html

Submissão em: 27/06/2017

Revisão em: 15/09/2017

Aceite em: 17/11/2017

Lisandra Espíndula Moreira é Psicóloga, Mestra em Psicologia Social e Institucional/UFRGS, Doutora em Psicologia/UFSC e docente do departamento de Psicologia da Universidade Federal de Minas Gerais/ FAFICH. https://orcid.org/0000-0001-9356-3416

Endereço para correspondência: FAFICH - Departamento de Psicologia. Av. Antônio Carlos, 6627. Pampulha. Belo Horizonte/MG, Brasil. CEP 31270-901 E-mail: lisandra.ufmg@gmail.com 